\title{
Online Secure Examination Process using M-Learning Techno
}

\author{
Kavya G. S. ${ }^{1}$, Ragini A. ${ }^{1}$, Rashmitha R. ${ }^{1}$, Sandhya R. ${ }^{1}$, Prof. Vijayanirmala B. ${ }^{2}$ \\ UG Scholar, Dept of Computer Science and Engineering, Jnana Vikas Institute of Technology, Bidadi, Ramanagara ${ }^{1}$ \\ Professor of Computer Science and Engineering, Jnana Vikas Institute of Technology, Bidadi, Ramanagara ${ }^{2}$
}

\begin{abstract}
M-Learning has enhanced the e-learning by making the learning process learner-centered. However, enforcing exam security in open environments where each student has his/her own mobile/tablet device connected to a Wi-Fi network through which it is further connected to the Internet can be one of the most challenging tasks. In such environments, students can easily exchange information over the network during exam time. This paper aims to identify various vulnerabilities that may violate exam security in m-learning environments and to design the appropriate security services and countermeasures that can be put in place to ensure exam security. It also aims to integrate the resulting secure exam system with an existing, opensource and widely accepted Learning Management System (LMS) and its service extension to the m-learning environment, namely "Moodbile Project".
\end{abstract}

Keywords: e-learning, m-learning, Learning Management System (LMS), Access control, exam engine.

\section{INTRODUCTION}

Computer security (Also known as cyber security or IT Security) is information security as applied to computers and networks. The field covers all the processes and mechanisms by which computer-based equipment, information and services are protected from unintended or unauthorized access, change ordestruction. Computer security also includes protection from unplanned events and natural disasters. Otherwise, in the computer industry, the term security - or the phrase computer security - refers to techniques for ensuring that data stored in a computer cannot be read or compromised by any individuals without authorization. Most computer security measures involve data encryption and password. Data encryption is the translation of data into a form that is unintelligible without a deciphering mechanism. A password is a secret word phrase that gives a user access to a particular program or system.

The Classical approach to perform e-exam involves providing specific exam centers equipped with machines configured with static security policy to be used only for exam purpose. This approach brings about the cost of creation and upkeep of the environment, and continuous underutilization thereof.

Also such polices cannot be applied in m-learning environments where the student's mobile/tablet devices are meant to be used for general purpose, e.g. Internet browsing or e-book reading, as well as for the sake of exams. Using student's mobile devices as exam stations offers the advantage of low cost, more exam takers at the time, and no need for a wired network. Thus, a dynamic security policy is needed in this case with an appropriate enforcing mechanism.

\section{PROPOSED SYSTEM}

This paper aims to design a Secure Exam Management System (SEMS) that meets the distinct security requirements of $\mathrm{m}$-learning environment and to integrate it with the current Moodle/Moodbile platform. This will result in a complete LMS that is both equipped with secure exam services and suitable for m-learning. Our intention of integrating SEMS with a well-known LMS such as Moodle is so to get benefits of Moodle's readymade services in other learning aspects such as course material administration, documentation, etc., However, the proposed SEMS can also work as a standalone secure exam management system for m-learning environments without integration with Moodle.

We developed a new Quiz Engine that can be deployed as a service oriented application, so that its services can be consumed by m-learning specific security requirements. As well, it should be able to integrate with Moodle/Moodbile in order to have a complete LMS which suites the m-learning environment and address all of its security issues.

\section{IMPLEMENTAION}

This project consists of three Modules they are: Student Module, Teacher Module and Admin Module.

\subsection{Student Module:}

This module is developed in Client Side (Android). Here students by typing exam name can write the appropriate exams. Students after writing exams can view their results using the Secret key generated at the time of registration. 
Students have to memorize their secret key to view their own results.

\subsection{Teacher Module:}

This module is developed in Client Side (Android). View all the students result. Schedules exam and inform the students about exam Equations.

\subsection{Admin Module:}

This module is developed Server Side (PHP). View all the student details. Immediately removes the student name from table after the completion of exams. So the students can't access again. Views all the student results and can remove the secret key so that student can view. Result only for particular period of time.

\section{INPUT DESIGN AND OUTPUT DESIGN}

The input design is the link between the information system and the user. It comprises the developing specification and procedures for data preparation and those steps are necessary to put transaction data in to a usable form for processing can be achieved by inspecting the computer to read data from a written or printed document or it can occur by having people keying the data directly into the system. The design of input focuses on controlling the amount if input required, controlling the errors, avoiding delay, avoiding extra steps and keeping the process simple. The input is designed in such a way so that it provides security and ease of use with retaining the privacy. Input Design considered the following things:

1. What data should be given as input?

2. How the data should be arranged or coded?

3. The dialog to guide the operating personnel in providing input.

4. Methods for preparing input validations and steps to follow when error occur.

\subsection{Objectives:}

Input Design is the process of converting a user-oriented description of the input into computer-based system. This design important to avoid errors in the data input process and show correct direction to the management for getting correct information from the computerized system. It is achieved by creating user-friendly screens for the data entry to handle large volume of data. The goal of designing input is to make data entry easier and to be free from errors. The entry screen is designed in such a way that all the data manipulates can be performed. It also provides record viewing facilities. When the data is entered it will check for its validity. Data can be entered with the help of screens. Appropriate messages are provided as when needed so that the user will not be maize of instant. Thus the objective of input design is to create an input layout that is easy to follow.

\subsection{System Architecture:}

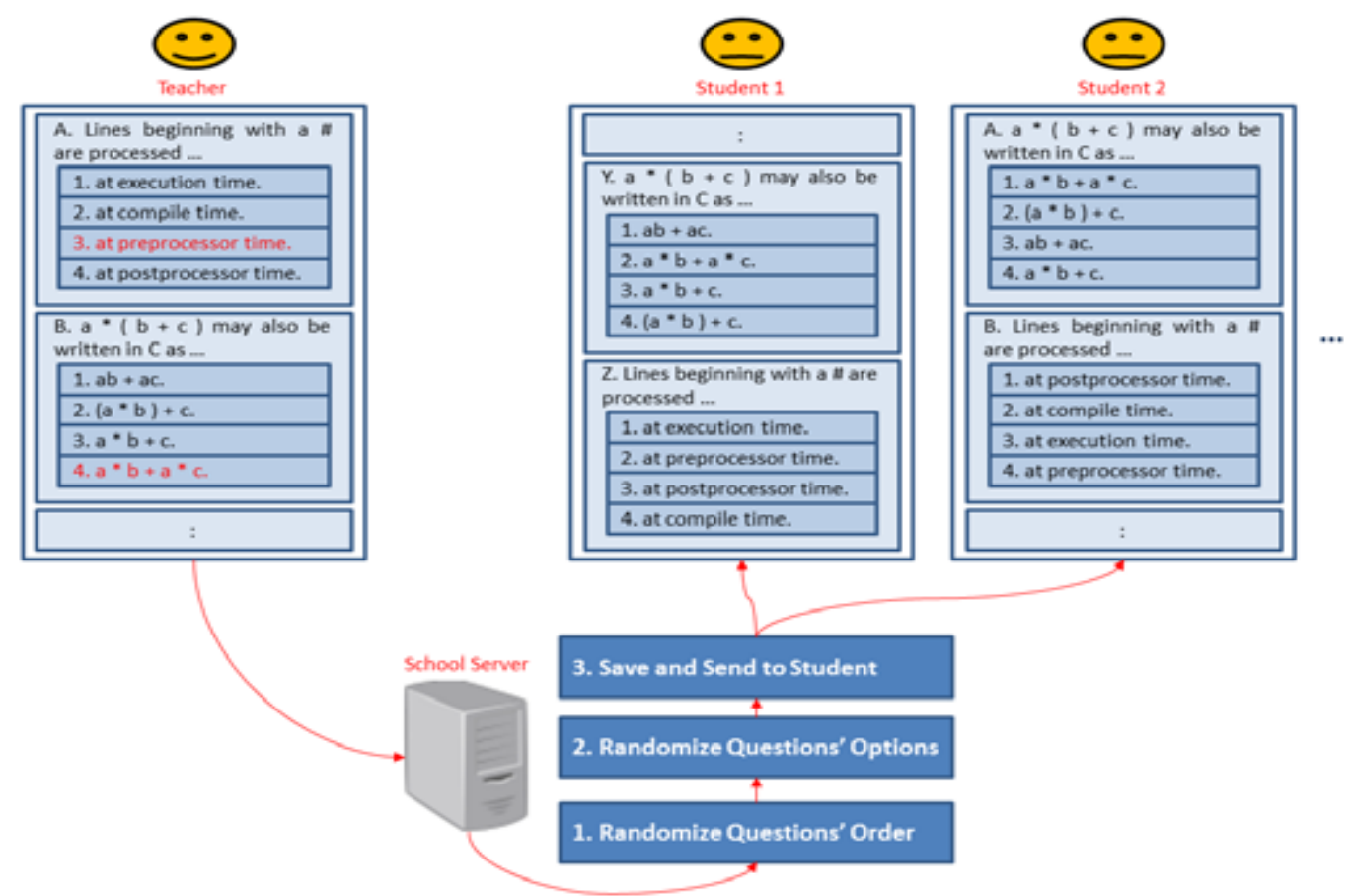

Figure 1: Architecture of Proposed System 


\section{SYSTEM STUDY}

The feasibility of the project is analyzed in this phase and business proposal is out forth with a very general plan for the project and some cost estimates. During system analysis the feasibility study of the proposed system is to be carried out. This is to ensure that the proposed system is not a burden to the company. For feasibility analysis, some understanding of the major requirements for the system is essential.

Three key considerations involved in the feasibility analysis are:

5.1. Economical Feasibility:

This study is carried out to check the economic impact that the system will have on the organization. The amount of fund that the company can pour into the research and development of the system is limited. The expenditures must be justified. Thus the developed system as well within the budget and this was achieved because most of the technologies used are freely available. Only the customized products had to be purchased.

\subsection{Technical Feasibility:}

This study is carried out to check the technical feasibility, that is, the technical requirements of the system. Any system developed must not have a high demand on the available technical resources. This will lead to high demands being placed on the client. The developed system must have modest requirements; as only minimal or null changes are required for implementing this system.

\subsection{Social Feasibility:}

The aspect of study is to check the level of acceptance of the system by the user. This includes the process of training the user to use the system efficiently. The user must not feel threatened by the system, instead must accept it as a necessity. The level of acceptance by the users solely depends on the methods that are employed to educate the user about the system and to make him familiar with it. His level of confidence must be raised so that he is also able to make some constructive criticism, which is welcomed, as he is the final user of the system.

\section{CONCLUSION}

This paper process the design of a Secure Exam Management System (SEMS) to migrate the unique exam security threats that exist in m-learning environments. SEMS offers many exams services such as: secure and random distribution of exam questions, turbo-mode assessment, prevention of the "unattended exam" issue, biometric-based authentication service for anti-impersonation, preventing students from exchanging their devices during exam, conducting exam securely through online or offline strategies, and auditing. The paper also provides countermeasures against various network related issues such as network overload, occasional network failures, students attempting information during an exam, and an intruder using a Wi-Fi jammer to bring the WI-FI network down. SEMS is integrated with an open source and widely accepted LMS, namely Moodle and its Moodbile services extension. The resulting design is a complete LMS with secure exam services that can be consumed by legacy systems through web browsers as well by m-learning systems. Finally, a survey conducted reveals that overall attitude of students and teaches towards SEMS are very favorable.

\section{REFERENCES}

[1] "Think Act - Corporate Learning Goes Digital", Roland Berger Strategy Consultants, https://www.rolandberger.com/ media/pdf/Roland_Berger_TAB_Corporate_Learning_E_20140602.pdf. May 2014.

[2] "2014 Training Industry Report", Training Magazine, http://www.trainingmag.com/sites/default/files/magazines/2014_11/2014-IndustryReport.pdf. Nov/Dec 2014.

[3] M.P. Prendes, "PLATAFORMAS DE CAMPUS VIRTUAL CON HERRAMIENTAS DE SOFTWARE LIBRE: Análisis comparativode la situación actual en las universidades españolas," Informe del Proyecto EA-2008-0257 de la Secretaría de Estado de Universidades e Investigación, 2009.

[4] G. Yamamoto and C.H. Aydin, "E-learning in Turkey: Past, Present and Future", e-Learning Practices, vol. 2, MidaseBook. Pp. 961-987, 2010

[5] S. Wexler, N. Grey, D. Miller, F. Nguyen, and A. Barnevelda, "Learning Management Systems: The good, the bad, the ugly and the truth," The E-learning Guild, May 2008.

[6] "Learning Management Systems Market by Users - Worldwide Market Forecasts and Analysis 2013 - 2018," MarketsandMarkets, http://www.marketsandmarkets.com/Market-Reports/learning-management-systems-market-1266.html. Oct. 2013.

[7] L. Johnson, S. A. Becker, V. Estrada, and A. Freeman, "NMC Horizon Report: 2015 Higher Education Edition," The New Media Consortium, https://net.educause.edu/ir/library/pdf/HR2015.pdf. 2015. 